\title{
Tecnologias para Aprender e Ensinar
}

\author{
*Prof ${ }^{a}$ Joelene de Oliveira de Lima \\ ***Prof ${ }^{a}$ Mara Franceli Ribeiro Pacheco
}

This text shows the narrative of an experience about the construction of computerized children's Games made as a common activity among different subjects in the same scholar environment. It is shown some considerations about the experienced challenges by the students from Normal Course and the computer teachers from the area of Informática Aplicada à Educação e Didática. The students of second level of high school, using Everest 6.0 as a multimedia authoring tool, built games to be put into practice with Kindergarten, levels A and B. This theme was part of a pre-trainee in Didática da Educação Infantil (Didacticism of Kindergarten) with a practical application. The theme "The Vegetable Garden" resulted in a scholar vegetable garden and it was the inspiration to produce a CD with children's games.

Resumo: Este texto apresenta o relato de experiência na construção de Jogos Infantis computadorizados, elaborados como atividade interdisciplinar dentro de um ambiente escolar. São apresentadas algumas considerações à cerca dos desafios vivenciados pelos alunos do Curso Normal e das professoras da área de Informática Aplicada à Educação e Didática. Com a utilização da ferramenta de autoria multimídia Everest 6.0, alunos do $2^{\circ}$ do Ensino Médio construíram jogos para serem aplicados nos níveis A e B da Educação Infantil. A temática escolhida já fazia parte do pré-estágio na disciplina de Didática da Educação Infantil com a aplicação prática de campo. O tema "A Horta" resultou em uma horta escolar e foi a inspiração para a produção do CD com jogos infantis.

\section{Introdução}

O Projeto "TECNOLOGIAS PARA APRENDER E ENSINAR" surgiu da necessidade de aplicação prática dos conhecimentos adquiridos nas disciplinas de Didática da Educação Infantil e de Informática Aplicada à Educação.

O projeto foi desenvolvido pelos alunos do $2^{\circ}$ ano do Ensino Médio Modalidade Normal de

2002, com a utilização da ferramenta de autoria multimídia Everest 6.0. A turma optou pela temática "A horta" por estarem desenvolvendo com os alunos da Educação Infantil e da $1^{a}$ série do Ensino Fundamental a prática de ensino na implantação de uma horta escolar dentro do tema transversal Educação Ambiental. 


\section{Objetivo da Disciplina de Didática}

Proporcionar aos educandos do Curso Normal, conhecimentos e fundamentos teóricos que possibilitem a aprendizagem de uma prática pedagógica consciente, criativa, democrática, valorizadora do ser humano. Através da utilização diferentes recursos que facilite a transição de saberes para desencadear a reflexão, o interesse e o prazer no processo de aprender e ensinar.

\section{Objetivo da Disciplina de Informática}

A disciplina de Informática aplicada a Educação se propõem a discutir a possibilidade do uso do computador como recurso pedagógico. Dando noções básicas de Informática, explorando os diferentes recursos pedagógicos do computador e elaborando projetos contemplando o uso do computador como recurso.

\section{Desenvolvimento}

O objetivo do projeto "TECNOLOGIAS PARA APRENDER E ENSINAR" é propiciar aos educandos do curso normal a experiência de criar jogos didáticos de caráter lúdico e pedagógico com o auxílio dos recursos multimídia.

No final de 2000, recebemos o software Everest para desenvolver projetos na escola, pois já havíamos lido muito a respeito de sua aplicação no contexto escolar. Após um estudo do seu uso e recursos, planejamos as etapas do trabalho e começamos a modelagem dos jogos

As primeiras experiências foram realizadas com as turmas do curso com temática aleatória e que não foram aplicados com as crianças pois estávamos no final do terceiro trimestre.

Neste ano optamos por um tema central de escolha dos alunos e cada dupla criou uma atividade diferente dentro desse tema. Após a escolha do tema o grupo criou um personagem o qual chamaram "Wilbor" que é o apresentador do jogo.

Esse projeto tem um caráter prático, pedagógico e experimental desde o desenho e digitalização do personagem aos demais elementos do jogo.

Estabelecemos um roteiro com o grupo com a criação de um portfólio onde deveria constar relato diário, um artigo pesquisado sobre como criar jogos para crianças, planejamento das telas do jogo, plano de aula sobre a utilização do jogo criado e avaliação do trabalho feito pela dupla.

Fizemos a digitalização das imagens do livro (enviamos um e-mail para as autoras) e pedimos autorização para uso interno. Elas responderam que podíamos usar o livro (imagens).

Quanto ao layout do jogo, a preocupação era com o aporte didático e pedagógico do mesmo. Fizemos a locução das instruções para os diferentes jogos com a modulação de voz diferente, imitando voz de criança, uma vez que o personagem deve agradar esse 
público. As regras de gerenciamento dos elementos da interface e funcionamento do jogo forma escritas com a linguagem de script do Everest.

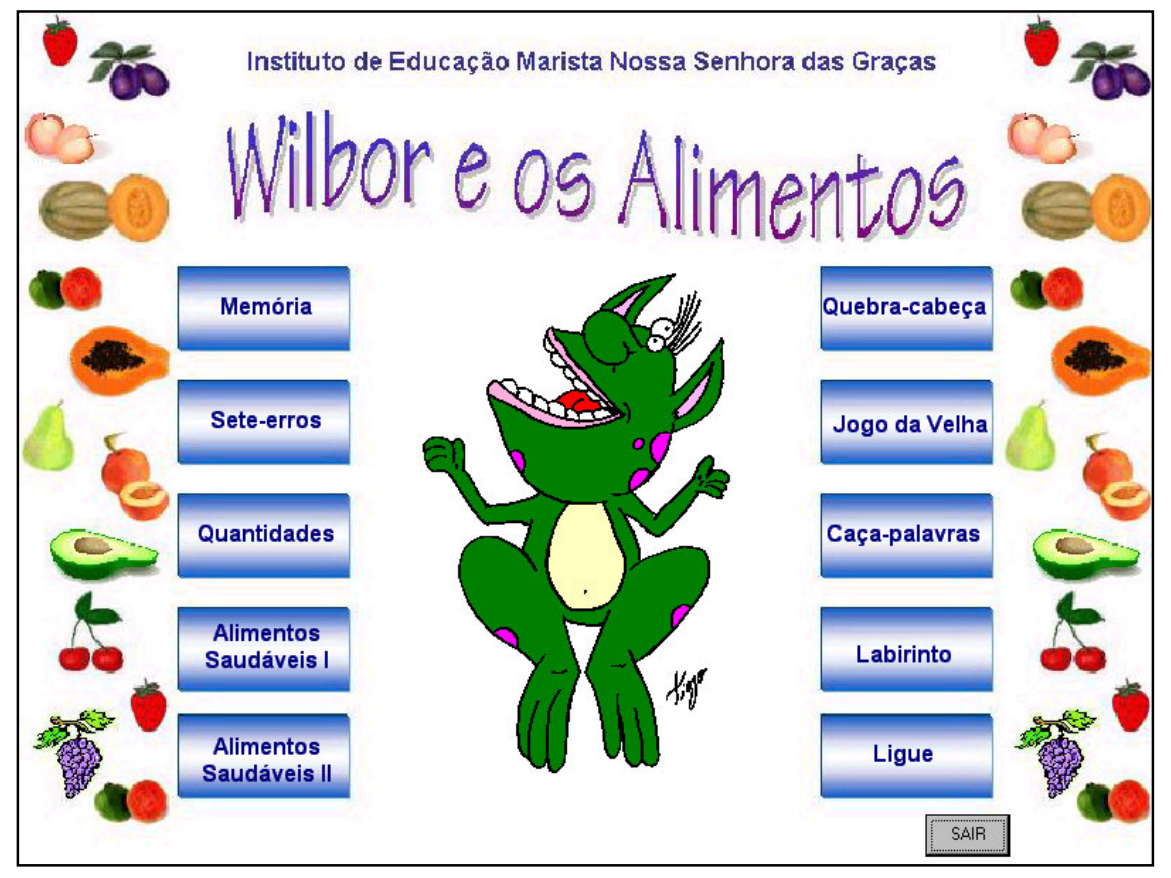

Figura 1: Interface inicial, menu de acesso aos jogos

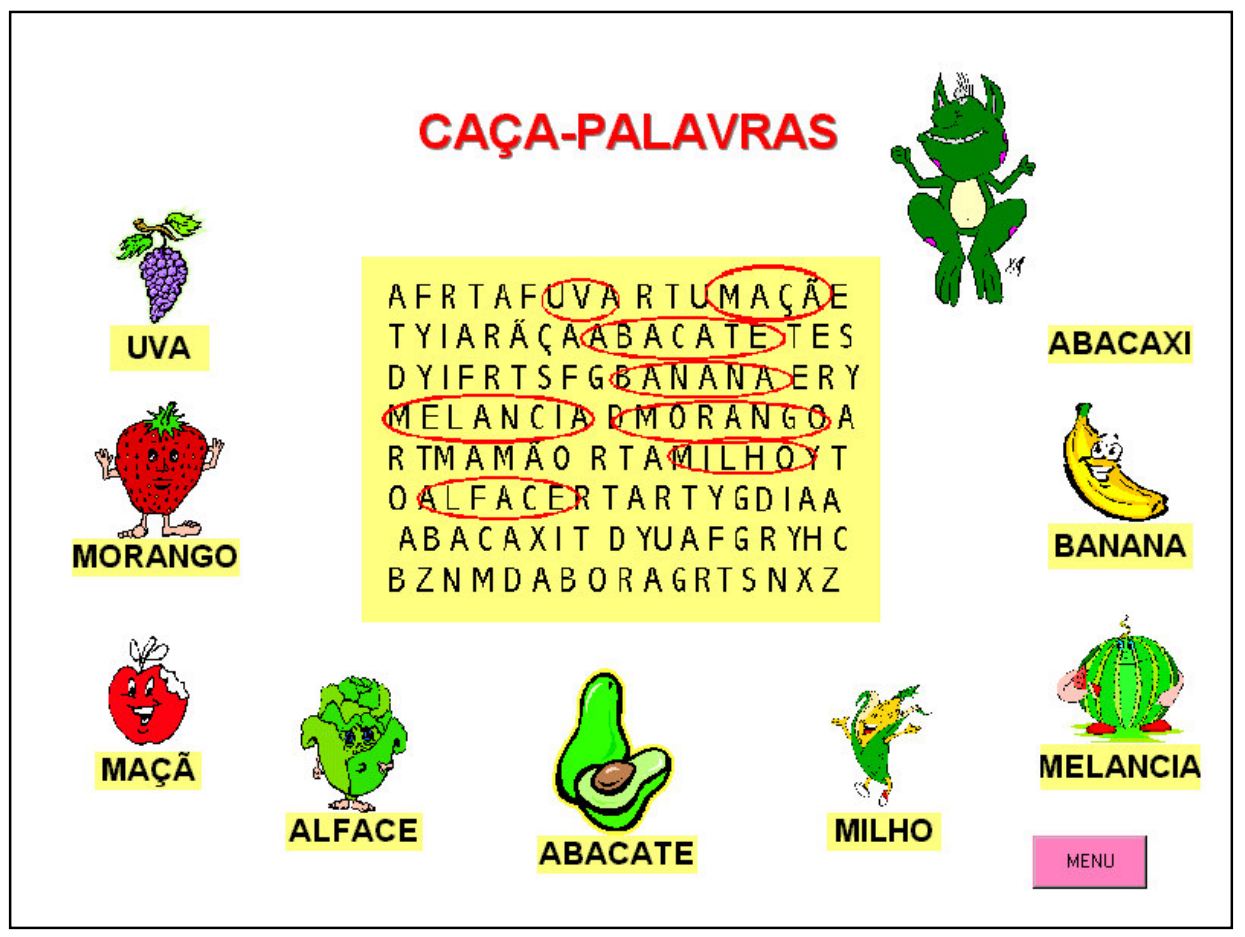

Figura 2: Interface de um dos jogos criados pelos normalistas, caça-palavras. 
Nesse processo, tivemos a intenção de propor vivências, radicadas no cotidiano familiar da criança, utilizando muitas imagens interessantes, já que é nessa fase que inicia o processo de socialização e alfabetização e o reconhecimento dos signos alfabéticos. Acrescentamos, ainda, um incentivo a cada acerto do aluno, valorizando suas pequenas vitórias. Ao abrir o jogo tem um Мenu de opções.

A cada clique o aluno ouve o nome do local onde clicou ou o nome da palavra ou objeto em que clicou para que, possa relacionar ao comando do jogo. Existe um aviso ao aluno, se ele acertou ou não a atividade

O fruto das pesquisas e práticas de laboratório realizadas no período de setembro a dezembro de 2002 é um CD de jogos intitulado : "Wilbor e os Alimentos". Esses jogos serão aplicados nas práticas de ensino com as turmas de Educação Infantil e $1^{\text {a }}$ série do Instituto no ano de 2003.

Não imaginamos que levaríamos tanto tempo executando o projeto, pois a ferramenta não necessita de linhas de programação e a maior vantagem do uso do Everest é, justamente, a possibilidade de gerar executáveis de forma pouco complexa. No entanto, os detalhes de layout, a gravação do som, o próprio gerador do executável e os testes para ver se estava tudo funcionando ocuparam $50 \%$ do tempo dedicado ao trabalho.

Havia uma vontade da turma de integrar o uso do computador ao processo de aprendizagem já existente em sala-de-aula. Um dos objetivos era integrar os conceitos já trabalhados de forma lúdica, utilizando um ambiente computadorizado, com interface agradável e disponibilizando recursos de simples manuseio aos alunos: $\mathrm{O}$ desafio estava lançado, o que fazer?

Aprendemos muito sobre o uso da ferramenta. Foi nossa primeira experiência criando jogos dessa forma. Após esse trabalho vários outros jogos poderão surgir.

Com a nossa experiência e o desenvolvimento de várias aplicações definimos uma metodologia interna de trabalho que passamos a descrever a seguir:

\section{1) Definição do Tema:}

Tópico a ser desenvolvido para que a tela tenha seu ponto de partida.

2) Roteiro e Plano de Ação:

Subtemas e detalhes, plano onde conterá os dados tela a tela. Uma espécie de rascunho do trabalho final.

3) Pesquisa:

Coleta de dados, análise e organização das informações, imagens, textos, vídeos, sons...

4) Registro das Informações Coletadas:

Etapa técnica, digitação e a organização dos dados para o computador

5) Apresentação: 
Demonstração do projeto para o grupo e a criação de um CD com o executável do programa.

6) Testagem:

Aplicação prática com as turmas que participaram do projeto.

Criação do Jogo na Escola:

Prof ${ }^{a}$ Mara Franceli Pacheco

Disciplina: Didática Geral e Didática da Educação Infantil

e Prof ${ }^{a}$. Joelene de Oliveira de Lima

Disciplina: Informática Aplicada à Educação

Revisão ortográfica: Prof ${ }^{a}$ Rosana Hammarströn

*Joelene de Oliveira de Lima Especilista em Informática na Educação

** Mara Franceli Pacheco Especialista em Educação Infantil - Ensino Médio

Modalidade Normal - Informática Aplicada a Educação e Didática da Educação

Infantil - Instituto de Educação Marista Nossa Senhora das Graças - Viamão/RS

gracas@maristas.org.br www.maristas.og.br/gracas 


\section{Referências Bibliográficas}

Coleção No Reino da HORTOLÂNDIA . Ilustrações Darlion Amorin e Gilson Nardes Vol. I e II . Editora: Sabida - 1999

Coleção No Reino da FRUTOLÂNDIA. Ilustrações Darlion Amorin e Gilson Nardes Vol. I e II . Editora: Sabida - 1999

COELHO, Nelly Novaes. Literatura Infantil, Teoria e Análise Didática. Ed. Ática 1991

AROEIRA, Maria Luiza. Didática de Pré-Escola. Editora FTD - 1999

; ANTUNES, Cláudia. Novas linguagens em leitura. In: Bortolini, A. ; Souza, V. Mediação tecnológica: construindo e inovando. Porto Alegre: EDIPUCRS, 2003. p.419-40.

CRAIDY, Carmem Maria. KAERCHER, Gládis Elise Pereira da Silva. Educação Infantil: pra que te quero? Porto Alegre, Secretaria do trablho, cidadania e assistência social - Departamento de Assistência, 1998

FRANCO, Sérgio Roberto Kieling. O construtivismo e a Educação. Porot Alegre, Editora Mediação, 1997.

LÉVY, Pierre. As tecnologias da inteligência. O futuro do pensamento na era da informática. Rio de Janeiro, Editora 34, 1998

PERRENOUD, Philippe 10 Novas Competências para Ensinar, São Paulo: Artmed, 2000 .

RODRIGO, Maria José; ARNAY, José. Domínios do conhecimento, prática educativa e formação de professores. A construção do conhecimento escolar, 2. São Paulo: Ática, 1997.

SANDHOLTZ, Judith Haymore. Ensinando com tecnologia: Criando salas de aula centradas nos alunos. Editora Artes médicas - 1997 
SILVA, Marco. Sala de aula interativa. Rio de Janeiro: Quartet, 2000.

TIJIBOY, Ana Vilma; MAÇADA, Débora Laurinó; SANTAROSA, Lucila Maria Costi e FAGUNDES, Léa da Cruz. Aprendizagem cooperativa em ambientes telemáticos. Informática na Educação: teoria e prática. V.2, $\mathrm{n}^{\mathrm{o}}$ 1, maio, 1999, p. 19-28.

VARELA, Francisco J. ; MATURANA, Humberto. Romesín. De máquinas e seres vivos. Autopoiese - a organização do vivo. Porto Alegre: Artes Médicas, 1997.

VYGOTSKY , Lev S., "A Formação Social da mente", São Paulo: Martins Fontes, 1984. 